\title{
Inappropriate $\mathrm{ADH}$ secretion caused by oat cell carcinoma and relieved by lung resection
}

\author{
CLAYTON ROBINSON, ROY C JEFFRIES, AND GEORGE C WALSH
}

From the University of British Columbia, Vancouver, Canada

In this case report we describe a patient with an early oat cell carcinoma and inappropriate antidiuretic hormone (ADH) secretion, whose symptoms were cured by resecting the tumour. The follow-up period is four and a half years. Another unusual feature, the presence of thrombocytopaenia, was greatly improved by the lung resection.

\section{Case report}

Mrs MS, aged 62 years, was first admitted to hospital on 12 May 1975. Her complaints were tiredness and a dry cough for four months, intermittent constipation and looseness of bowels for two months, and hypertension for six years. This had been treated with methyl-dopa, but the drug had been stopped three months previously because she had developed thrombocytopaenia, and instead, she was given propranolol and hydrochlorothiazide. She had had a right radical mastectomy for infiltrating duct carcinoma of the scirrhous type five years earlier.

Physical examination showed a blood pressure of $210 / 110$, the right breast was missing, and sigmoidoscopy was negative. Other investigation results were: haemoglobin $13.8 \mathrm{~g} / \mathrm{dl}$, white blood count $6.6 \times 10^{9} / 1$ with normal differential, ESR 34, platelet count $56 \times 10^{9} / 1$, (48 three months earlier). Prothrombin time $100 \%$, partial thromboplastin time $33 \mathrm{~s}$, sternal marrow normal, serum electrolytes: sodium $111 \mathrm{mmol} / 1$, potassium $4 \cdot 3 \mathrm{mmol} / 1$, calcium and phosphorus normal, serum protein, alkaline phosphatase, and LDH normal, T4 and T3 and serum cortisol normal.

A chest radiograph showed a pleural reaction and thickening along the left major fissure, and this had been present a year earlier. Gastrointestinal and skull radiographs and pyelography were normal as was urinalysis. A bone scan showed a slight increase in uptake in the right fronto-parietal region, and the spine in particular was normal.

It was postulated that the thrombocytopaenia might be secondary to medication. Another possibility was that the bone might be involved by metastatic breast cancer, but the platelets were the only blood constituent affected. It was felt

Address for reprint requests : Dr CLN Robinson, Thoracic and Cardiovascular Surgery, 808 Fairmont Medical Building, 750 West Broadway, Vancouver, BC V5Z 1H7, Canada. possible that inappropriate $\mathrm{ADH}$ secretion was caused by a lung tumour, although the chest radiograph was normal. The patient had been a heavy smoker from the age of 15 years and had an irritating cough for the previous four months. She was discharged and arrangements were made for admission to another hospital to investigate the possibility of a lung tumour.

The next admission was from 24 June to 11 July 1975. In the course of a month, the chest radiograph had changed and now showed atelectasis of the left upper lobe and a mass at the left upper lobe hilum. A bronchoscopy showed complete stenosis of the left upper lobe bronchus and partial stenosis of the left lower lobe bronchus. A biopsy of the left upper lobe bronchus revealed tumour of an undifferentiated type. Bronchoscopically, the lesion was resectable by pneumonectomy.

Further investigations were done. A liver scan was normal. Serum sodium and chloride are shown in fig 1. Serum osmolality was $232 \mathrm{~m} \mathrm{osmol} / \mathrm{kg}$.

It was felt that the tumour was an early one and that surgical treatment would give the best chance of cure. Fluids were restricted to one litre per day, to correct the hyponatraemia.

She had a left thoracotomy on 4 July. At operation, the left upper lobe was atelectatic and the lower lobe was expanded. There was a tumour at the upper lobe hilum $4 \mathrm{~cm}$ in diameter. There

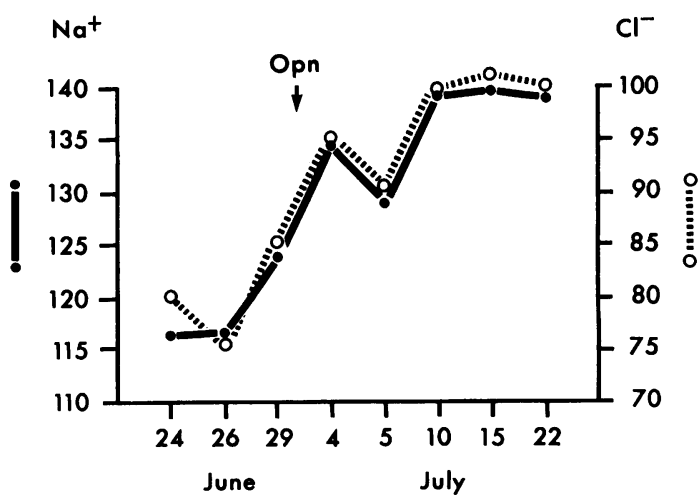

Fig 1 Plasma levels of $\mathrm{Na}^{+}$and $\mathrm{Cl}$ before and after lung resection. 
were lymph nodes up to $7 \mathrm{~mm}$ in size behind the phrenic nerve. There was a $1 \mathrm{~cm}$ node in front of the trachea, above the carina, and the subcarinal nodes were slightly enlarged and firm. A left intrapericardial pneumonectomy was performed. An enlarged node was removed from under the ligamentum arteriosum and sent separately for examination. Histology of the resected tumour showed it to be an undifferentiated carcinoma arising at the origin of the upper lobe bronchus (fig 2). Several nodes at the upper lobe hilum were replaced with tumour. However, the nodes under the ligamentum arteriosum and the one in front of the trachea showed replacement with breast carcinoma (fig 3).

The patient had an uninterrupted recovery from the pneumonectomy. The values for serum sodium and chloride are shown in fig 1 . Two weeks after operation the serum osmolality was normal.

In the late postoperative period she complained of an unusual amount of lower lumbar pain. A radiograph of the lumber spine at this time showed osteoblastic abnormalities in the second, third, and fourth lumbar vertebrae. These lesions were thought to be caused by metastases from the breast cancer and not from the lung cancer. This was borne out in the further progress of the patient. On account of the metastases in the lung hilum and the mediastinum she had a course of Cobalt treatment to the

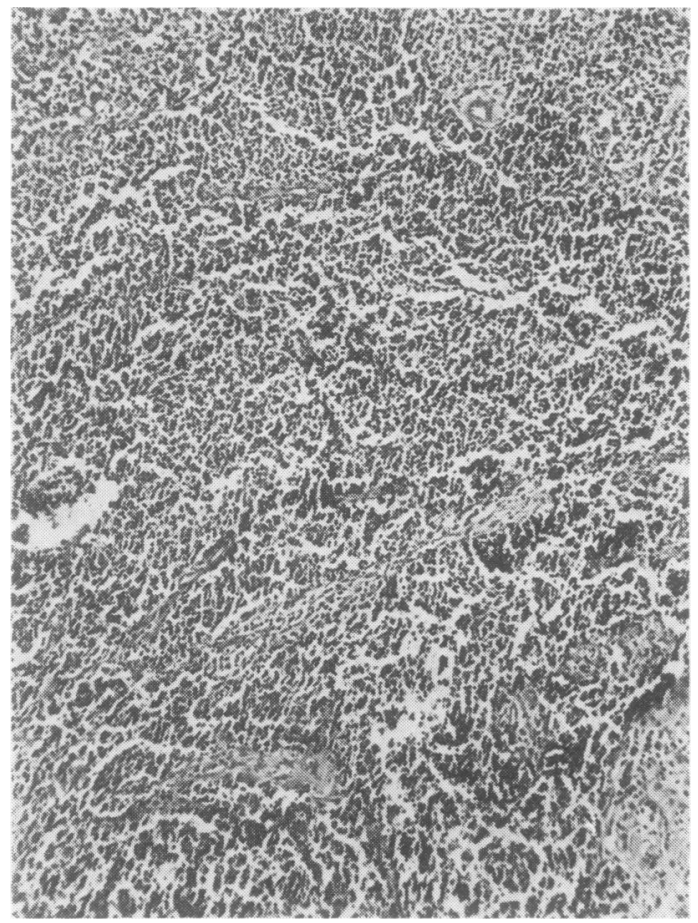

Fig 2 Photomicrograph of undifferentiated cell bronchial tumour, original magnification $\times 125$, $H$ and $E$.

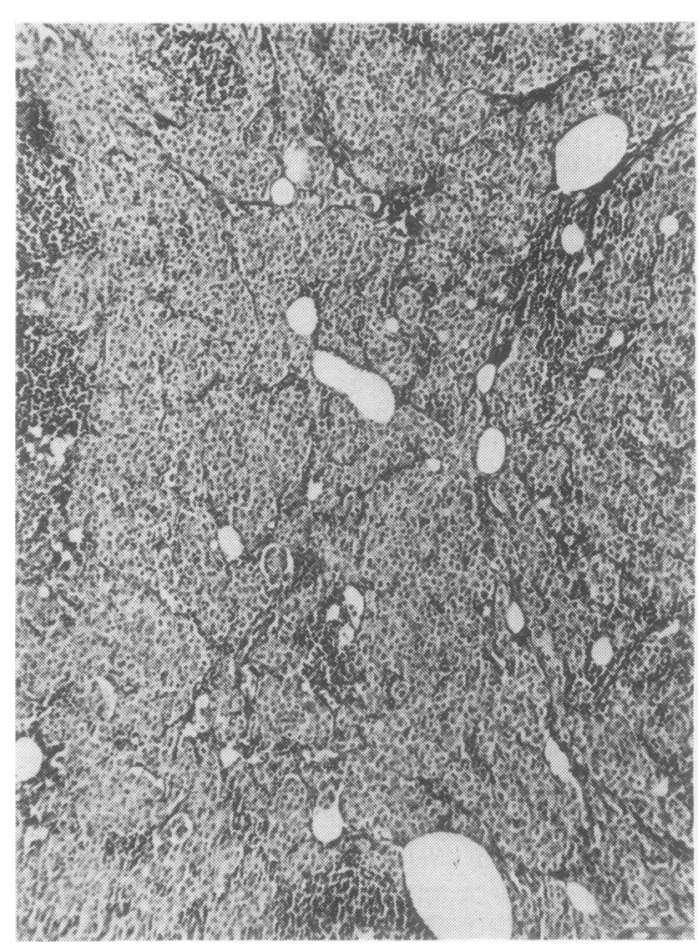

Fig 3 Photomicrograph of mediastinal node metastasis from breast cancer scirrhous-spheroidal cells, original magnification $\times 175, H$ and $E$.

mediastinum starting six weeks after the operation. The total dose was 3000 rads given in two opposing parallel fields.

One year after the pneumonectomy, because of moderately severe pain in the lumber spine, she. was given a course of Cobalt treatment to the lumbar spine with good palliation. In addition she was treated with intermittent diethyl stilbestrol $10 \mathrm{mg} O$ daily from September 1975 to January 1978.

The platelet count increased from $50 \times 10^{9} / 1$ before응 resection to $220 \times 10^{9} / 1$ immediately afterwards, and $>$ fell gradually to the $100 \times 10^{9} / 1$ range, but of course, metastases to the spine from the previous breast cancer had developed by that stage. The electrolyteser have remained at a normal level since removal of $N$ the lung tumour.

\section{Discussion}

This patient had normal renal function before $\frac{0}{\mathscr{C}}$ operation, normal thyroid and adrenal function and $\stackrel{?}{?}$ hypo-osmolality. The anti-diuretic state was partially 0 relieved by water restriction and permanently cor- $\overline{0}$ rected by removing the lung tumour. The main- $\overrightarrow{\mathbb{D}}$ tenance of normal plasma sodium after the operation $\frac{\mathcal{P}}{\mathbb{D}}$ without water restriction suggests that the tumour 0 was responsible for the production of antidiuretic hormone. 
Inappropriate ADH secretion has been found in many diseases. ${ }^{1}$ It has been managed simply with water restriction, or the administration of demeclocycline, or lithium carbonate (to produce a nephrogenic diabetes insipidus). A causative tumour has been treated by operation, ${ }^{2} 3$ Cobalt irradiation, ${ }^{4}$ and nitrogen mustard,, 5 all with short-term success. Relief for four and a half years from the complication of inappropriate ADH secretion has not been recorded previously.

\section{References}

1 Winkler AW, Crankshaw OF. Chloride depletion in conditions other than Addison's disease. J Clin Invest 1938; 17:1-6.

2 Utiger RD. Inappropriate antidiuresis and carcinoma of the lung: detection of arginine vasopressin in tumour extracts by immunoassay. $J$ Clin Endocrinol Metab 1966; 26:970-4.

3 Tisher CC. Correction of an ADH syndrome by resection of a bronchogenic carcinoma with demonstration of tumour antidiuretic activity. Clin Res 1966; 14:185.

4 Bower BF, Mason DM, Forsham PH. Bronchogenic carcinoma with inappropriate antidiuretic activity in plasma and tumour. $N$ Engl $J$ Med 1964; 271:934.

5 Ivy HK. Renal sodium loss and bronchogenic carcinoma. Arch Intern Med 1961; 108:115-23. 